\title{
ATUAÇĀO DA UFSM NAS PESQUISAS DO GONDWANA SUL-BRASILEIRO
}

Pedro L. P. Sartori (Depto. Geociências - CCNE/UFSM)

Na década de 60, o primeiro trabalho de natureza geológi ca, desenvolvido pela UFSM, resultou na denominação da Formação Tü panciretã $(1,2)$ que foi caracterizada como sendo uma seqtência sedi mentar que recobre as rochas vulcânicas da Formação Serra Geral, na região do Planalto Médio do Rio Grande do Sul, área esta tida até então como de ocorrência do Arenito Botucatu que aí afloraria gra ças à existência de uma janela estratigräfica.

No início dos anos 70, numa sintese sobre o relevo do Rio Grande do sul foi proposta uma tipologia das transições geomorfoló gicas entre o Escudo Sul-rio-grandense e os demais compartimentos topogräficos, com a hipótese de poder existir três tipos de contato: por depressão denudacional e cuestas, por depressão denudacional e exumação, e contato por falhas (3).

$\mathrm{Na}$ mesma época foi realizado o mapeamento geológico do Mu nicípio de São Francisco de Assis, na escala 1:100.000, totalizando uma Irea de $4.122 \mathrm{Km}^{2}$ (4). Deste trabalho resultou, posteriormente, a caracterização petrográfica da sequência de rochas vulcânicas da Formação Serra Geral no rebordo ocidental do Planalto Meridional, bem como o estabelecimento do limite ocidental das ocorrências gera das pelo vulcanismo ácido que cobriu os derrames de natureza basál tica, no Rio Grande do Sul, através de uma linha, aproximadamente norte-sul, passando 4,5 quilômetros a leste de Unistalda e coincí dindo com a encosta superior do Planalto (5).

Na mesma região, foram descritos aspectos estruturais de natureza tectônica que coincidem com o contorno do rebordo do $\mathrm{Pl}$ a nalto Meridional, na porção oeste do Rio Grande do Sul. Esta tectô nica está manifestada pela presença de uma estrutura maior, em antí forme, que coincide com $\circ$ eixo de arqueamento do Escudo Sul-riomran dense (6).

Na região de Santa Maria, foi estabelecida, pela primeira vez, a estratigrafia dos derrames de lavas da Formação Serra Geral, 
com a identificação de uma seqthência básica inferior, representada por derrames de composição andesito-basáltica toleítica, e outra áci da superior, de composição riodacítica, constituída por derrames de granófiros e de vitrö́firos $(7,8)$.

A caracterização dessas duas seqtências de rochas vulcâni cas que compõem a Formação Serra Geral, aliada ao estudo geoquímicc dos isōtopos de estrôncio, permitiu constatar que houve uma partici pação importante de material oriundo do Manto superior e, também, da Crosta Inferior na evolução da atividade vulcânica na Bacia do Paraná, durante o Cretáceo (9).

Posteriormente, na década de 80 , essa diversidade de tí pos petrográficos que compõe a Formação Serra Geral foi descrita, também, nos estados de Santa Catarina (10), Paraná (11) e São Pau $10(12)$.

Com relação à mineralogia das rochas basālticas, o estudo da composição, leis de macla e estado estrutural dos plagioclásios de distintos derrames, na região de Santa Maria, permitiu maior pre cisão no cálculo das porcentagens de anortita e no estudo da histó ria térmica das lavas (13).

Paralelamente à estratigrafia dos derrames de lavas na região de Santa Maria, o estudo dos Arenitos Intertrapps (14) demons trou que eles mantêm íntima correlação com os arenitos eólicos da Formação Botucatu, tendo com os mesmos continuidade lateral em cer tos locais.

No estudo de paleocorrentes da Formação Botucatu, na mes ma região, chegou-se a uma grande média de $\mathrm{N} 24^{\circ}$ para a direção prin cipal dos ventos, enquanto que nas Folhas de Montenegro, Novo Ham burgo, Taquara, Gravataí e São Leopoldo, obteve-se a determinação de uma direção predominante do vento oriunda do quadrante SW, indi cando que os alíseos de inverno provenientes do sul eram os que do minavam a deposição na área. A presença de paleoventos do $\mathrm{N}$ e $\mathrm{NE}$ de monstrou, também, a participação, mesmo que minorităria, dos ventos alíseos de verão $(15,16)$.

o reestudo da estratigrafia da seqthência sedimentar gon dwânica na região de Santa Maria, elevou para a categoria de Forma ção o Membro Caturrita, bem como a passagem para Membros, dos Fácies Alemoa e Passo das Tropas da Formação Santa Maria (15).

Os trabalhos de campo realizados durante o mapeamento geo lófico das Folhas de Santa Maria e Camobi (17), propiciaram a veri ficação das relações de contato entre as diversas unidades estratị gráficas que ocorrem na região (18).

Na porção oeste do Rio Grande do Sul, o estudo preliminar sobre a gênese dos campos de areia no Município de Quaraí permitiu constatar que são devidos ao retrabalhamento das seqlências quaternärias 
e não das formações gondwânicas (19). De outra parte, a ărea de ocor rência da Formação Botucatu, nas Folhas Manoel Viana e são Francis co de Assis, não parece ser tão extensiva, sendo o substrato meso zöico constituido, principalmente, por um arenito fluvial, similar ao Membro Passo das Tropas da Formação Santa Maria. Sedimentos qua ternārios distribuem-se por grandes extensões (20).

Com referência à intemperização das rochas vulcânicas da Formação Serra Geral, o primeiro trabalho desenvolvido na região de Santa Maria, destacou os aspectos mineralógicos e geoquímicos rela tivos à alteração dessas rochas, tendo-se constatado mobilidade acn tuada dos elementos alcalinos e alcalinos-terrosos, com preservação significativa da sílica e fixação total do Fe e Al. No plano minera lógico, observou-se a formação predominante de esmectita e, por ou tro lado, de caulinita e illita desenvolvidas a partir dos derrames de rochas ácidas (21). Posteriormente, novos estudos verificaram a seqtência de alteração dos minerais, caracterizando a seguinte esca la de estabilidades relativas: carbonaro $<$ piroxênio $=$ vidro $<$ pla gioclásio < feldspato alcalino < magnetita < quartzo (22). O proces so de alteração dessas rochas foi caracterizado como bissialitiza ção, próximo ao limite da monossialitização (22) .

O estudo comparativo das argilas dos sedimentos gondwâni cos (formações Rosārio do Sul, Santa Maria e Caturrita) e cenozói cos da Depressão CEntral do Rio Grande do Sul, permitiu constatar que nos primeiros predomina a montmorilonita, seguida da illita e de camada mixta I-M, enquanto nos segundos hă amplo predomínio de caolinita e pequena quantidade de illita, camada mixta I-M e montmo rilonita (23).

Do ponto de vista geotécnico, trabalhos desenvolvidos so bre as formações gondwânicas na região de Santa Maria forneceram di versas informações sobre, por exemplo, a localização de zonas de maior instabilidade para fundações, espessuras e tipos de solos, o comportamento das formações em taludes e túneis, a ocupação das en costas da Serra Geral, bem como quanto a localização dos rejeitos sólidos, exploração de água subterrânea e de pedreiras $(24,25,26$, $27,28)$.

No âmbito da Paleontologia, tem maior significado: uma re senha dos fatos ligados aos jazigos de fósseis dos municípios de San ta Maria e de São Pedro do Sul. (29); a taxonomia de um tecodonte aetossáurio, descrito como Aetosauroides subsulcatus sp. nov., loca lizado na Zona-Associação de Rhynchocephalia da Formação Santa Ma ria, indicando idade no Ischigualastense Inferior (30); um trabalho voltado para a preservação dos fósseis paleobotânicos de são Pedro do Sul, RS (31), bem como a edição, pela UFSM, da tradução da obra "Répteis Fósseis do Gondwâna Sul-americano" de Huene (32). 
Por último, em relação às rochas fossiliferas do aflora mento de São Sepé, evidências geológicas e paleontológicas demons traram que pertencem à Formação Palermo, com os sedimentos tendo $5 \underline{1}$ do depositados em ambiente continental, contendo uma microflora de idade kunguriana (33).

\section{REFERENCIAS BIBLIOGRAFICAS}

(1) MENEGOTTO, E.; SARTORI, P.I. \& MACIEL FILHO, C.L. 1968. Nova Se quência Sedimentar sobre a Serra Geral no Rio Grande do Sul. UFSM. Santa Maria. Inst. Solos e Cult., Publ. Esp. nol, 19p.

(2) MENEGoTTO, E. 1980. Análise textural da Formação Tupanciretã. Ciência e Natura, Santa Maria, 2:91-103.

(3) MÜLLER FILHO, I.L. 1970. Notas para o estudo da geomorfologia do Rio Grande do Sul, Brasil. UFSM. Santa Maria. Dep. Geoc., Pubz. Esp. no 1, 34p.

(4) MACIEL FILHO, C.L.; MENEGOTTO, E. \& SARTORI, P.I. 1971. Geolo gia do Municipio de São Francisco de Assis, RS. UFSM. Santa Maria - CEB. Publ. Esp. no 4, 29p.

(5) SARTORI, P.L. \& MACIEL FILHO, C.L. 1976. Petrografia da seqthên cia vulcânica da Formação Serra Geral no rebordo ocidental do Planalto Meridional, RS. In: CONGR. BRAS. de GEOL., 290, Ouro Preto, Anais... vol. 2:297-307.

(6) MACIEL FILHO, C.L. \& SARTORI, P.L.P. 1979. Aspectos estruturais da região de São Francisco de Assis, RS. Ciência e Natura, Santa Maria, 1:53-65.

(7) SARTORI, P.L.; MACIEL FILHO, C.L. \& MENEGOTTO, E. 1975. Contrí buição ao estudo das rochas vulcânicas da Bacia do Paraná na região de Santa Maria, RS. Rev. Bras. de Geoc., São Paulo, $5(3): 141-159$.

(8) SARTORI, P.L.P. \& GOMES, C.B. 1980. Composição químico-mineraló gica das últimas manifestações vulcânicas da Bacia do Paraná na região de Santa Maria, RS. An. Acad. Bras. de Ciências, Rio de Janeiro, $52(1): 125-133$.

(9) CORDANI, U.G.; SARTORI, P.L.P. \& KAWASHITA, K. 1980. Geoquímica dos isōtopos de estrôncio e a evolução da atividade vulcâni ca na Bacia do Paraná (Sul do Brasil) durante o Cretãceo.An. Acad. Bras. de Ciências, Rio de Janeiro, 52(4):811-818.

(10) SARTORI, P.L.P.; BORTOLOTTO, O.J. \& KAWASHITA, K. 1982. Os prin cipais tipos de rochas vulcânicas da Bacia do Paraná no Pla nalto de Santa Catarina. Ciência e Natura, Santa Maria,4:7184 .

(11) SARTORI, P.L.P. 1984. As principais ocorrências de rochas vulcâa nicas ácidas da Formação Serra Geral no Planalto do Paraná. In: CONGR. BRAS. de GEOL., 339, Rio de Janeiro, 1984. Anais ... vol. IX:4539-4547. 
(12) SARTORI, P.L.P. \& MACIEL FILHO, C.L. 1983. Petrografia das ro chas ácidas da Formação Serra Geral na região do Rio Parana panema, São Paulo. Ciência e Natura, Santa Maria, 5:19-23.

(13) SARTORI, P.L.P. 1980. Composição, leis de macla e estado estrü tural dos plagioclásios de rochas vulcânicas da Bacia do Pa raná. Ciência e Natura, Santa Maria, 2:105-113.

(14) VEIGA, P. 1973. Estudo dos Arenitos "Intertrapps" da Formagão Serra Geral na região de Santa Maria-RS. Curso de Pós-Grad. em Geoc., UFRGS. Porto Alegre, Diss. de Mestrado, 88p.

(15) MEDEIROS, E.R. 1980. Estratigrafia do Grupo São Bento na região de Santa Maria e Paleocorrentes da Formasão Botucatu. Curso de Pós-Grad. em Geoc., UfRGs. Porto Alegre, Diss. de Mestra do, $135 p$.

(16) BOSSI, G.E.; PICOLLI, A.E.M.; PILATTI, F.; THOMAZ, S.L.; JABUR, I.C.; RODRIGUES, M.A. \& MEDEIROS, E.R. 1977. Paleocorrentes da Formação Botucatu nas Folhas de Montenegro, Novo Hambur go, Taquara, Gravataí e São Leopoldo, RS. Acta Geol. Leopol densia, UNISINOS, Est. Tec., II(3):83-109.

(17) MACIEL FILHO, C.L. (Ed.). 1988. Mapa Geológico da Folha de Ca mobi-RS. MAPA, Santa Maria, 1:1-10.

(18) MACIEL FILHO, C.L. (Ed.). 1989. Mapa Geológico da Folha de San ta Maria-RS. UFSM. Santa Maria.

(19) SARTORI, P.L.P.; VEIGA, P.; GASPARETTO, N.V.L.; MACIEL FILHO, C.L. \& MEDEIROS, E.R. 1987. As relações estratigráficas en tre as formações geológicas da Bacia do Paraná na região de Santa Maria, RS. In: SIMP. SUL-BRAS. de GEOL., 3\%, Curitiba, 1987. Atas ... vol.1:379-392.

(20) VEIGA, P.; MEDEIROS, E.R. \& SUERTEGARAY, D.M.A. 1987. A gênese dos campos de areia no Município de Quarai-RS. In: CONGR. da ASSOCI. BRAS. de EST. do QUATERNÁRIO, Porto Alegre, Anais ... vol.1:367-377.

(21) MEDEIROS, E.R.; MÜLLER FILHO, I.L. \& VEIGA, P. 1989. O mesozöị co no oeste do Estado do Rio Grande do Sul. In: SIMP. SULBRAS. de GEOLOGIA, 3\%, Porto Alegre... Atas 1. Acta Geol. Leopoldensia, XII(29): 49-60.

(22) SARTORI, P.L.; MACIEL FILHO, C.L. \& MENEGOTTO, E. 1973. Contri buição ao estudo das rochas basālticas e seus produtos de alteragão na região de Santa Maria, RS. helatório FAPERGS, Santa Maria, 10lp.

(23) MENEGOTTO, E. \& GASPARETTO, N.V.L. 1987. Intemperização de ro chas vulcânicas ācidas e básicas na região de Santa Maria, RS. In: CONGR. BRAS. de GEOQUIMICA, 1\%, Porto Alegre, Anais ... vol. 2:69-83.

(24) VEIGA, P. 1979. Estudo comparativo das argilas de rochas meso zóicas e cenozóicas da Depressão Central do Rio Grande do 
Sul. Ciência e Natura, Santa Maria, 1:67-78.

(25) MACIEL FILHO, C.L. 1977. Caracteriząão geotécnica das forma gões sedimentares de Santa Maria, RS. UFRJ, Inst. de Geoc., Rio de Janeiro, Diss. de Mestrado.

(26) CONSTANZO JUNIOR, J.; VIRGILI, J.C. \& MACIET, FILHO, C.L. 1978. In: CONGR. BRAS. GEOL. ENG., 2\%, são Paulo, Anais... vol. $1: 267-280$.

(27) MACIEL FILHO, C.I. 1978. Mapeamento geotécnico e planejamento da ocupação urbana de Santa Maria, RS. In: CONGR. BRAS. de GEOL. ENG., 2\%, São Paulo. Anais... vol.1:257-265.

(28) MACIEL FILHO, C.L. \& OSORIO, L.C.E. 1981. As argilas expansi vas e o fraturamento de paredes em Santa Maria, RS. In: CON GR. BRAS. de GEOL. ENG., 30, Itapema, Anais... vol.3:205-219.

(29) MACIEL FILHO, C.L. 1984. Casos de ocupação das encostas da Ser ra Geral no Rio Grande do Sul. In: CONGR. BRAS. de GEOL. ENG, 4\%, Belo Horizonte, Anais... vol. 2:81-87.

(30) BELTRÃo, R. 1965. Paleontologia de Santa Maria e são Pedro do Sul - Rio Grande do Sul - Brasil. Bol. da Univ. Fed. de San: ta Maria, Inst. de Ciênc. Nat., Santa Maria, 2:1-114.

(31) ZACARIAS, J. 1981. Uma nova espécie de tecodonte Aetossaurio Aetosauroides subsulcatus sp. nov. da Formagão Santa Maria, Triássico do Rio Grande do Sul, Brasil. UFRGS, Curso de Pós-Grad., Porto Alegre, Diss. de Mestrado.

(32) ZACARIAS RONDINEL, J.; MINELLO, L.F.; MACIEL FILHO, C.L. 1986. Preservação dos fósseis paleo-botânicos de São Pedro, RS Brasil. In: ENCONTRO EST. do ENS. de BIOL., 18, UFSM, Santa Maria, Atas... 88-95.

(33) HUENE, F.F. von. 1990. Répteis Fósseis do Gondwana Sul-America no. CCNE. Depto. de Geociências. UFSM. Santa Maria, RS, 353p.

(34) BORTOLUZzI, C.A. \& VEIGA, P. 1981. Considerações sobre a gaolo gia da área dos afloramentos fossiliferos de São Sepé, RS. Pesquisas, Porto Alegre, 14:23-36.

Palestra proferida na abertura do Encontro. 